\title{
O Discurso Da Intolerância Contra A Mulher Nas Redes Sociais
}

\author{
El Discurso De La Intolerancia Contra La Mujer En Las Redes Sociales
}

The Discourse Of Intolerance Against Women In Social Networks

\author{
Luciane Alves Branco Martins ${ }^{1}$
}

\begin{abstract}
Resumo
O presente trabalho tem por objetivo analisar o discurso intolerante contra a mulher nas redes sociais, especificamente no Facebook. Com a internet, a intolerância se propagou, sendo a mulher um alvo constante de insultos. A misoginia, a incitação ao estupro, o assédio moral e outros tipos de violência estão se tornando recorrentes no ambiente virtual e são amplamente disseminados por meio de discursos divulgados por perfis "fakes" ou por pessoas que se identificam. Nesse contexto, as comunidades do Facebook que se autodenominam machistas compartilham discursos de ódio ou repúdio contra as mulheres. Sendo assim, a escolha desse tema justifica-se pela reflexão crítica que se faz necessária sobre como a mulher tem sido exposta a discursos intolerantes nas redes sociais. A rede social escolhida foi o Facebook, devido às inúmeras comunidades de cunho machista que defendem seu posicionamento. A metodologia utilizada para esse trabalho iniciou com a pesquisa dos termos "machismo" e "machista", nessa rede social. A partir disso, foram escolhidas algumas comunidades para a análise de seus discursos intolerantes, com o auxílio da referência bibliográfica em livros, revistas, artigos científicos e sites. O referencial teórico fundamenta-se pelas ideias do Círculo de Bakhtin, referindo-se às noções de dialogismo, enunciado e signo ideológico. Essa análise pretende dar conta de como é construída discursivamente a intolerância contra a mulher na referida rede social.
\end{abstract}

Palavras-chave: Bakhtin; Discurso; Facebook; Intolerância; Mulher

\section{Resumen}

El presente trabajo tiene por objetivo analizar el discurso intolerante contra la mujer en las redes sociales, específicamente en Facebook. Con la internet, la intolerancia se propagó, siendo la mujer un blanco constante de insultos. La misoginia, la incitación a la violación, el acoso moral y otros tipos de violencia se están volviendo recurrentes en el ambiente virtual y son ampliamente difundidos por medio de discursos divulgados por perfiles "fakes" o por personas que se identifican. En ese contexto, las comunidades de Facebook que se autodenominan machistas comparten discursos de odio o repudio contra las mujeres. Siendo así, la elección de este tema se justifica por la reflexión crítica que se hace necesaria sobre cómo la mujer ha sido expuesta a discursos intolerantes en las redes sociales. La red social elegida fue Facebook, debido a las innumerables comunidades de cuota machista que defienden su posicionamiento. La metodología utilizada para ese trabajo inició con la investigación de los términos "machismo" y "machista", en esa red social. A partir de eso, fueron escogidas algunas comunidades para el análisis de sus discursos intolerantes, con el auxilio de la referencia bibliográfica en libros, revistas, artículos científicos y sitios. El referencial teórico se fundamenta por las ideas del Círculo de Bajtín, refiriéndose a las nociones de dialogismo, enunciado y signo ideológico. Este análisis pretende dar cuenta de cómo se construye discursivamente la intolerancia contra la mujer en la referida red social.

Palabras claves: Bajtín; Discurso; Facebook; Intolerancia; Mujer

\begin{abstract}
The present work aims to analyze the intolerant discourse against women in social networks, specifically on Facebook. With the internet, intolerance has spread, and women are a constant target of insults. Misogyny, incitement to rape, bullying and other types of violence are becoming recurrent in the virtual environment and are widely disseminated through speeches spread by fake profiles or by people who identify themselves. In this
\end{abstract}

\footnotetext{
${ }^{1}$ Mestranda em Linguística PUC-RS; Porto Alegre; RS; Brasil; luciane2910@gmail.com
} 
context, self-styled, sexist Facebook communities share hate speech or repudiation of women. Therefore, the choice of this theme is justified by the critical reflection that is needed on how women have been exposed to intolerant discourses in social networks. The social network chosen was Facebook, due to the countless sexist communities that defend its position. The methodology used for this work began with the search of the terms "machismo" and "macho" in this social network. From this, some communities were chosen for the analysis of their intolerant discourses, with the aid of bibliographical reference in books, magazines, scientific articles and websites. The theoretical framework is based on the ideas of Bakhtin's Circle, referring to the notions of dialogism, enunciation and ideological sign. This analysis intends to explain how discursively the intolerance against women in the said social network is constructed.

Keywords: Bakhtin; Facebook; Intolerance; Speech; Woman

\section{Introdução}

A discriminação contra a mulher é um fato histórico em nossa sociedade. Com o advento da internet, esse preconceito se propagou, sendo a mulher um alvo constante de insultos. A misoginia se alastra nesse contexto, assim como a incitação ao estupro, o assédio moral e outros tipos de violência, que fomentam um discurso compartilhado no ambiente virtual.

No anonimato, por meio de perfis "fakes", ou mesmo se identificando, a intolerância contra as mulheres é amplamente divulgada em mensagens desrespeitosas. São inúmeras as comunidades do Facebook que se autodenominam "machistas", nas quais o discurso de ódio ou repúdio contra as mulheres é disseminado constantemente.

A escolha do tema da intolerância contra a mulher nas redes sociais justifica-se necessidade de uma reflexão crítica sobre como a mulher tem sido exposta a discursos intolerantes e machistas nas redes sociais. Para a análise dos discursos intolerantes sobre a mulher, a rede social escolhida foi o Facebook, em virtude das inúmeras comunidades que defendem esse posicionamento.

A metodologia utilizada para esse trabalho iniciou com a pesquisa do termo "machismo", no Facebook, resultando em uma lista de cerca de 30 comunidades. A partir disso, foram escolhidas três comunidades para a análise, que propagam e reproduzem o discurso intolerante contra a mulher. Foi utilizada a referência bibliográfica, em livros, revistas, artigos científicos e sites, para a análise desses discursos.

O referencial teórico desse estudo será fundamentado pelas ideias do Círculo de Bakhtin, referindo-se às noções de dialogismo, enunciado e signo ideológico. Essa análise pretende refletir sobre como é construída discursivamente a intolerância contra a mulher na referida rede social. 


\title{
2. Discursos Intolerantes Nas Redes Sociais
}

As redes sociais vêm sendo um campo no qual os discursos de ódio e intolerância estão se disseminando na internet. Nesse sentido, importante saber qual o conceito de redes sociais. Segundo Recuero (2009, p. 104),

Sites de redes sociais propriamente ditos são aqueles que compreendem a categoria dos sistemas focados em expor e publicar as redes sociais dos atores. São sites cujo foco principal está na exposição pública das redes conectadas aos atores, ou seja, cuja finalidade está relacionada à publicação dessas redes.

É negável o poder de comunicação das redes sociais, tanto para difundir notícias verdadeiras ou falsas. Nunca se falou tanto em Fake News, ou seja, notícias falsas espalhadas por veículos ou usuários pelos mais variados motivos e, nesse contexto, os discursos intolerantes se multiplicam.

O conceito de intolerância faz parte da nossa sociedade há séculos, porém, conforme o mundo foi se transformando, esse conceito também se modificou (MARCONDES, 2008, p.35).

\begin{abstract}
Segundo Bobbio (1992, p. 2003), a princípio, o termo era usado ao se tratar apenas de aceitação ou não da religião ou postura política de minorias. Desse modo, quando os filósofos dos séculos XVII e XVIII, John Locke e Voltaire, escreveram sobre esse tema em suas respectivas obras Carta acerca da Tolerância e Tratado sobre a Tolerância, preocupavam-se com a intolerância religiosa, muito praticada naquele momento. Hoje o termo foi generalizado e é também utilizado ao se referir à intolerância direcionada a qualquer tipo de minoria (étnica, lingüística etc.).

Cardoso (2003, p. 57) também observou que na modernidade o conceito de intolerância/tolerância sofreu ampliação, pois no renascimento o termo tolerância se referia basicamente à liberdade religiosa e já no século XIX, esse passou a referir-se à liberdade de pensamento, de expressão e de ações. Assim, acreditamos ser necessário diferenciar o sentido desses dois tipos de intolerância: 1.intolerância a crenças e opiniões diversas, que implica um discurso sobre a verdade. Ex. intolerância política e religiosa; 2 . intolerância face ao diferente, por motivo físico ou social. Ex. intolerância com o negro, o pobre, o homossexual, entre outros. Para Bobbio (1992:204), esses dois sentidos de intolerância possuem diferentes causas. "A primeira deriva da convicção de possuir a verdade; a segunda deriva de um preconceito".
\end{abstract}

Os discursos de intolerância na internet não se adequam a um gênero textual ou do discurso, pois

para definir um gênero é necessária a estabilidade de composição, de temática e de estilo, no âmbito de uma dada esfera de ação (religiosa, midiática, escolar, familiar, etc.). Os discursos intolerantes participam de várias esferas de ação ou mesmo de todas, e têm composição e estilos também diferentes, só podendo ser classificados 
tematicamente, ou seja, pela organização do plano do conteúdo [...] Em outras palavras, no caso dos discursos intolerantes, há apenas "estabilização" temática, pois há discursos intolerantes em diferentes esferas de atividades (política, religiosa, familiar), de gêneros diversos (notícias, sermões, bate-papo, etc.) e de tipos diferentes (narrativo, descritivo, etc.). (BARROS, 2011, p. 01/02)

Os discursos da internet são, em sua maioria, embasados em emoções. Cada postagem, cada texto, cada discurso mostram, de alguma forma, características que o locutor apresenta e que, se as esconde em suas relações interpessoais, nas redes sociais, por estarem protegidos por perfis, se mostram claramente.

\begin{abstract}
"Os discursos intolerantes são, em relação às paixões construídas nos discursos (...), fortemente passionais, e seus sujeitos são, assim, sempre sujeitos apaixonados. Predominam, nesses discursos, dois tipos de paixões - as paixões ditas malevolentes (antipatia, ódio, raiva, xenofobia, etc.) ou de querer fazer mal ao sujeito que não cumpriu os acordos sociais acima mencionados, e as paixões do medo do "diferente" e dos danos que ele pode causar.” (BARROS, 2011, p. 07)

“(...) parece evidente que los discursos intimidatorios constituyen un fenómeno eminentemente discursivo y pragmático, por encima de lo estrictamente lingüístico. Funcionan como alimentador de tensiones previamente existentes entre grupos sociales, actualizándose en situación de enunciación a través de conflictos de interacción entre individuos concretos.” (MUÑOZ e CAPPONI, 2017, p.11)
\end{abstract}

O dialogismo é um dos conceitos mais importantes da obra do Círculo de Bakhtin.

Considerado como uma propriedade da língua, é por meio do diálogo que comunicamos aos outros o nosso pensamento (BAKHTIN, 2016, p.146).

A orientação dialógica é naturalmente um fenômeno próprio a todo discurso. Tratase da orientação natural de qualquer discurso vivo. Em todos os seus caminhos até o objeto, em todas as direções, o discurso se encontra com o discurso de outrem e não pode deixar de participar, com ele, de uma interação viva e tensa. Apenas o Adão mítico que chegou com a primeira palavra num mundo virgem, ainda desacreditado, somente este Adão podia realmente evitar por completo esta mútua orientação dialógica do discurso alheio para o objeto. Para o discurso humano, concreto e histórico, isso não é possível [...]. (BAKHTIN, 1998 [1975], p. 88)

O diálogo é construído na interação, na qual todos os dizeres relacionam-se com os dizeres anteriores e os dizeres futuros. Seu funcionamento dá conta do real uso da língua na situação comunicativa nas relações de sentidos entre dois enunciados concretos.

Ainda que o diálogo seja interior, há a presença ativa dos outros no meu diálogo, pois nosso discurso é construído na interação coma coletividade. Na teoria bakhtiniana, há uma compreensão coletiva de produção discursiva, ainda que o discurso seja realizado por uma só pessoa.

Dessa forma, o discurso das redes sociais é dialógico. O locutor projeta, idealiza, de alguma forma, o seu destinatário, no caso, quem concorda com suas ideias e quem não concorda também. Sabe que haverá réplica, pois seu discurso é polêmico e, portanto, passível de manifestações de todos os lados. 
Ao falar do discurso do outro, não podemos deixar de ocupar alguma posição dialógica em relação a ele, concordar e discordar dele, assumir diante dele uma posição polêmica, irônica, apresentá-la como uma posição verdadeira, de autoridade duvidosa, etc. Desse modo, existe neste caso uma relação de caráter dialógico com o discurso do outro. (BAKHTIN, 2016, p. 147)

"Não se trata de pensamento, mas de intercâmbio de pensamentos, não se trata de um enunciado (isolado e autossuficiente), mas de um intercâmbio de enunciados no âmbito de uma dada sociedade.” (BAKHTIN, 2016, p. 149). Assim sendo, locutor e interlocutor estão em um constante diálogo, nas redes sociais, buscando sempre uma compreensão ativa e responsiva.

"A estrutura do enunciado é uma estrutura puramente social. O enunciado, como tal, existe entre os falantes." (VOLÓCHINOV, 2017, p.225). Bakhtin (2003, p.22) disserta sobre enunciado, caracterizando-o como a "unidade real da comunicação discursiva". Ele é “individual e por isso pode refletir a individualidade do falante (ou de quem escreve), isto é, pode ter estilo individual.", sendo elemento ideológico e comunicativo.

O discurso somente existe na forma de enunciados concretos entre falantes. A alternância dos sujeitos do discurso define o limite de cada enunciado, conforme discorre Bakhtin (2003, p. 29):

"Os limites de cada enunciado concreto como unidade da comunicação discursiva são definidos pela alternância dos sujeitos dos discursos, ou seja pela alternância dos falantes. Todo enunciado - da réplica sucinta (monovocal) do diálogo cotidiano ao grande romance ou tratado científico - tem, por assim dizer, um princípio absoluto e um fim absoluto: antes do seu início, os enunciados de outros; depois do seu término, os enunciados responsivos de outros (ou ao menos uma compreensão ativamente responsiva silenciosa do outro ou, por último, uma ação responsiva baseada nessa compreensão). $\mathrm{O}$ falante termina seu enunciado para passar a palavra ao outro ou dar lugar à sua compreensão ativamente responsiva. $\mathrm{O}$ enunciado não é uma unidade convencional, mas uma unidade real, delimitada com precisão pela alternância dos sujeitos do discurso e que termina com a transmissão da palavra ao outro, por mais silencioso que seja o 'dixi' percebido pelos ouvintes [como sinal] de que o falante concluiu sua fala."

O diálogo, a discussão e a luta pressupõem uma inter-compreensão linguística. (BAKHTIN, 2016, p. 130) Nas fronteiras do enunciado dá-se a alternância dos sujeitos do discurso, O término de um enunciado é como que interrompido no possível discurso do outro. As fronteiras do enunciado são as fronteiras dos sujeitos do discurso, isto é, as fronteiras dialógicas. (BAKHTIN, 2016, p. 134/135)

O discurso do locutor e do interlocutor precisa um do outro. Nessa interdependência é que estabelecem uma compreensão dialógica e responsiva, pois, segundo Di Fanti (2015, p. 421),

Cada um, ocupando singularmente um lugar num tempo definido, pode ver no outro o que ele sozinho não consegue ver, pois são diferenciados horizontes de valor. Percebe-se assim uma relação de interdependência entre o eu e o outro, necessária para a constituição do sujeito, do discurso e do sentido. 
As comunidades do Facebook escolhidas, para a análise do discurso de intolerância e preconceito contra a mulher, apresentam em seus títulos os termos "machismo" ou "machista". A seguir serão brevemente apresentadas:

a) Prints Machistas: essa comunidade foi criada em 30 de março de 2013 e tem, aproximadamente, 274 seguidores.

Nessa comunidade, foi postada, no dia 31/03/2014, uma imagem, ou "meme", no qual uma mulher aparece com uma touca na cabeça, avental e uma espécie de uniforme, lavando uma panela e tendo mais louca suja para lavar. O enunciado que consta nessa imagem é "Ninguém é estuprada em casa lavando louça"

Nesse sentido, apesenta-se a noção de signo ideológico, que se relaciona com a consciência, a ideologia e a linguagem. Tudo que é ideológico faz parte de uma realidade e remete a algo que se encontra no mundo exterior, cujo significado se constitui ao refletir e refratar outra realidade.

\footnotetext{
"Essa cadeia ideológica se estende entre as consciências individuais, unindo-as, pois o signo surge apenas no processo de interação entre consciências individuais. E a própria consciência individual está repleta de signos. Uma consciência só passa a existir como tal na medida em que é preenchida pelo conteúdo ideológico, isto é, pelos signos, portanto, apenas no processo de interação social." (VOLOCHÍNOV, 2017, p. 95)
}

"Tudo o que é ideológico possui uma significação: ele representa e substitui algo encontrado fora dele, ou seja, um signo. Onde não há signo também, não há ideologia." (VOLÓCHINOV, 2017, p.91).

Nessa postagem, a ideia é de que a mulher deve estar em casa, nas lidas domésticas, pois, assim, estará livre do perigo de ser estuprada, ou seja, a recorrente história de que mulher serve para ser "do lar" e que esse é um campo seguro para ela. Cabe salientar que os casos de violência doméstica também iniciam nesse mesmo lar, no qual a mulher, segundo o discurso dessa imagem, estaria "protegida".

b) Machismo é amor: em agosto de 2017, foi postada uma imagem de um homem, com roupa de soldado, "salvando" uma mulher e uma criança. Nessa imagem, consta o enunciado "Aquele momento em que o seu feminismo é refutado".

Essa imagem estabelece a tensão no fato de que a mulher, sendo feminista, na visão do locutor, não precisaria da ajuda de um homem. É importante compreender que em uma situação de risco, como a que se apresenta nessa postagem, mulheres e crianças são salvas em 
primeiro lugar e isso tem a ver com a questão de sobrevivência e não de qual o gênero é o mais forte para lidar com essa situação.

c) Machista opressor: essa comunidade apresenta, em seu título, uma ironia, pois se utiliza de uma frase constante do discurso feminista. Na postagem do dia 17 de abril de 2018, apresenta uma imagem no qual um homem está olhando apara uma mulher, sorrindo, e o seguinte enunciado "Você é feminista e acha que os homens te oprimem. Me fale como é ser sustentada pelo marido."

Nesse discurso, o locutor espera uma compreensão responsiva por parte do interlocutor, pois seu discurso tem um destinatário certo, ou seja, as mulheres feministas. Há influência do ouvinte-interlocutor no discurso. No diálogo atua um ouvinte real, cujas réplicas são dadas e determinam as réplicas-respostas. "O enunciado é o mínimo daquilo que se pode responder, com que se pode concordar ou não concordar. Um enunciado nega ou afirma algo.” (BAKHTIN, 2016, p. 133)

Nota-se que o conteúdo das postagens das três comunidades, por obviedade, é sempre de cunho desrespeitoso em relação às mulheres. Há, claramente, uma discriminação de gênero, no qual a mulher sempre é desfavorecida. Acreditam em suas ideias, pois "todos os campos da ideologia usam a língua, mas cada um a seu modo.” (BAKHTIN, 2016, p. 139)

"O diálogo, a discussão e a luta pressupõem uma inter-compreensão linguística." (BAKHTIN, 2016, p. 130). Nas fronteiras do enunciado dá-se a alternância dos sujeitos do discurso, "O término de um enunciado é como que interrompido no possível discurso do outro. As fronteiras do enunciado são as fronteiras dos sujeitos do discurso, isto é, as fronteiras dialógicas.” (BAKHTIN, 2016, p. 134/135)

O discurso do locutor e do interlocutor precisa um do outro. Nessa interdependência é que estabelecem uma compreensão dialógica e responsiva.

Cada um, ocupando singularmente um lugar num tempo definido, pode ver no outro o que ele sozinho não consegue ver, pois são diferenciados horizontes de valor. Percebe-se assim uma relação de interdependência entre o eu e o outro, necessária para a constituição do sujeito, do discurso e do sentido. (DI FANTI, 2015, 421)

"O enunciado se forma entre dois indivíduos socialmente organizados." (VOLÓCHINOV, 2017, p.204). Toda compreensão é, em maior ou menor grau, prenhe de reação responsiva quer em palavras, quer em ação. (...) É justamente nessa compreensão ativa e responsiva que se fixa o discurso do falante (...) (BAKHTIN, 2016, p. 122)

No discurso, sempre se estabelece o que se fala e para quem se fala. Há uma projeção do destinatário idealizado. Nas três postagens analisadas, pode-se considerar o destinatário 
como os seguidores das respectivas comunidades, mas, houve, também, os supradestinatários, ou seja, as outras pessoas a quem essa mensagem atingiu além dos destinatários projetados, no caso, as mulheres que discordam do conteúdo postado.

\section{Considerações Finais}

O discurso intolerante e preconceituoso contra a mulher nas redes sociais é um fato que requer muita atenção por parte de todos. As mensagens de cunho machistas somente reforçam que precisamos percorrer um longo caminho para conquistar a igualdade de gênero.

E esse trabalho deve iniciar desde cedo, em casa, na educação dos filhos, estimulando o respeito ao próximo, coibindo as brincadeiras sem graça dividindo tarefas igualmente, sem distinção de gênero, ensinando que preferência de cor não define gênero, e que se as mulheres da casa não são respeitadas por sua própria família, não queiram que sejam respeitadas pelas famílias dos outros.

Quando essas crianças chegarem à escola, que elas já entendam que gênero não define inteligência, força, capacidade. Que meninas podem brincar com meninos nas mesmas brincadeiras e, que acima de tudo, todos devem conviver em harmonia e respeito. Crianças que compreendem a igualdade de gênero se tornam adultos que respeitam o próximo.

O que se nota, nas redes sociais, são pessoas que se escondem atrás da tela do computador por meio de perfis "fakes", ou mesmo se identificando para colocar para destilar todo o seu preconceito velado, característica muito presente em nossa sociedade. Em um discurso carregado de ódio e intolerância, a mulher tem sido alvo de inúmeras ofensas, insultos, misoginia, incitação ao estupro, assédio moral e outros tipos de violência, que fomentam um discurso sem embasamento, "curtido" e compartilhado no ambiente virtual.

São inúmeras as comunidades de perfis machistas no Facebook, nas quais disseminam o discurso de ódio ou repúdio contra as mulheres, por isso, a breve análise desses discursos faz-se necessária, pois crianças estão crescendo nesse ambiente de rancor desmedido, sem embasamento algum, pelo simples fato de, quem posta mensagens machistas, se sentir superior às mulheres. Há comunidades, inclusive, que querem acabar com o feminismo, pois é “contra a moral e os bons costumes". Bons costumes são o respeito ao próximo, à liberdade de expressão e saber que gênero não define caráter, competência, capacidade, inteligência, entre outros.

As redes sociais, seja qual for, devem ser um campo para o constante diálogo, respeito e que agregue aos envolvidos. O diálogo, a discussão e a luta pressupõem uma intercompreensão linguística. (BAKHTIN, 2016, p. 130), portanto, nesse contexto, é fundamental 
que haja respeito para que, realmente, exista um diálogo, com compreensão ativa e responsiva, afinal, a palavra é a ponte que liga eu ao outro. (VOLÓCHINOV, 2017, p.205)

A palavra como ato, ideologia, como bem defende Bakhtin, deve ser utilizada para construir diálogos enriquecedores entre locutores e interlocutores. E como se aprende dialogando, ouvindo, crescendo como pessoa.... Karl Max dizia que só uma ideia enunciada em palavra se torna pensamento real para o outro e só assim para mim mesmo. Esse outro, porém, não é apenas o outro imediato (o destinatário segundo), a palavra avança cada vez mais à procura da compreensão responsiva. (BAKHTIN, 2016, p. 105/106)

Cada postagem realizada nas redes sociais é mostra um pouco de cada locutor, pois cada pensamento meu, junto com seu conteúdo, é um ato ou ação que realizo - meu próprio ato ou ação individualmente responsável [postupok]. (BAKHTIN, 2010, p. 21). A responsabilidade de cada postagem denota o quanto ainda há de preconceito e intolerância nas redes sociais contra a mulher, uma vez que essas pessoas se reúnem em comunidades para exaltar o machismo, a misoginia e o preconceito.

\section{Referências}

BAKHTIN, Mikhail. Os gêneros do discurso. Trad. Paulo Bezerra. São Paulo: Editora 34, 2016.

Para uma filosofia do ato. Tradução de Carlos Alberto Faraco e Cristovão Tezza da edição americana Toward a philosophy of the act. Austin: University of Texas Press,1993. (tradução destinada exclusivamente para uso didático e acadêmico)

2003.

Estética da criação verbal. Tradução de Paulo Bezerra. São Paulo: Martins Fontes,

Questões de Literatura e de Estética: a teoria do romance. Tradução do russo por Aurora Fornoni Bernardini et al. $4^{\mathrm{a}}$ ed. São Paulo: UNESP; Hucitec, 1998 [1975].

BARROS, Diana. P. O discurso intolerante na Internet: enunciação e interação. XVIII Congreso Internacional Asociación de Lingüística y Filología de América Latina (ALFAL 2014). João Pessoa-Paraíba, Brasil.

A construção do discurso intolerante. Disponível em http://diversitas.fflch.usp.br/files/Texto\%20Profa.\%20Diana\%20Luz\%20Pessoa\%20de\%20B arros\%20(1).pdf Acesso em 14 jul. 2018.

Intolerância, preconceito e exclusão. In: Lara, G.P.; LIMBERTI, R.P. Discurso e (des)igualdade social. São Paulo: Contexto, 2015.

BOBBIO, Norberto. As Razões da Tolerância in BOBBIO, Norberto. A Era dos Direitos: Campus, 1992. 
CARDOSO, Clodoaldo M. Tolerância e seus limites - Um olhar latino-americano sobre diversidade e desigualdade. São Paulo: UNESP, 2003.

DI FANTI, Maria da Glória Corrêa. Discurso, mídia e produção de sentidos: questões de leitura e de formação na contemporaneidade. Revista do Programa de Pós-Graduação em Letras da Universidade de Passo Fundo, v. 11, n. 2, p. 418-438, jul/dez 2015.

MARCONDES, Iara Lucia. Os consultórios gramaticais: um estudo de preconceito e intolerância lingüísticos. (Dissertação apresentada ao Programa de Pós-Graduação em Língua Portuguesa do Departamento de Letras Clássicas e Vernáculas da Faculdade de Filosofia, Letras e Ciências Humanas da Universidade de São Paulo, para a obtenção do título de Mestre em Letras. Orientador: Profa. Dra. Marli Quadros Leite). Universidade de São Paulo - USP. São Paulo, 2008.

RECUERO, R. Redes Sociais na Internet. Porto Alegre: Sulina, 2009.

VOLÓCHINOV, V. Marxismo e filosofia da linguagem: problemas fundamentais do método sociológico na ciência da linguagem. Trad., notas e glossário de Sheila Grillo e Ekaterina Vólkova Aérico; ensaio introdutório de Sheila Grillo. São Paulo: Editora 34, 2017.

2013.

A construção da enunciação e outros ensaios. São Carlos: Pedro \&João Editores,

A palavra na vida e na poesia. Introdução ao problema da poética sociológica (1926). In: BAKHTIN, M. Palavra própria e palavra outra na sintaxe da enunciação. São Carlos: Pedro \& João Editores, 2011. 